\title{
Guiding of long-range surface plasmon polaritons along channels in periodic arrays of scatterers
}

Boltasseva, Alexandra; Hvam, Jørn Märcher; Nikolajsen, T.; Leosson, K.; Søndergaard, T.; Bozhevolnyi, S. I.

Published in:

2004 CLEO/IQEC Technical Digest CD-Rom

Link to article, DOI:

10.1109/IQEC.2004.241656

Publication date:

2004

Document Version

Publisher's PDF, also known as Version of record

Link back to DTU Orbit

Citation (APA):

Boltasseva, A., Hvam, J. M., Nikolajsen, T., Leosson, K., Søndergaard, T., \& Bozhevolnyi, S. I. (2004). Guiding of long-range surface plasmon polaritons along channels in periodic arrays of scatterers. In 2004 CLEO/IQEC Technical Digest CD-Rom IEEE. https://doi.org/10.1109/IQEC.2004.241656

\section{General rights}

Copyright and moral rights for the publications made accessible in the public portal are retained by the authors and/or other copyright owners and it is a condition of accessing publications that users recognise and abide by the legal requirements associated with these rights.

- Users may download and print one copy of any publication from the public portal for the purpose of private study or research.

- You may not further distribute the material or use it for any profit-making activity or commercial gain

- You may freely distribute the URL identifying the publication in the public portal 


\title{
Guiding of long-range surface plasmon polaritons along channels in periodic arrays of scatterers
}

\author{
A. Boltasseva and J. M. Hvam \\ COM, Technical University of Denmark, Bldg. 345v, DK-2800 Kgs. Lyngby, Denmark \\ aeb@com.dtu.dk \\ tel.: +4545256368 fax: +4545936581 \\ T. Nikolajsen, K. Leosson, T. Sendergaard, and S. I. Bozhevolnyi \\ Micro Managed Photons A/S, Ryttermarken 15, DK-3520, Farum, Denmark
}

\begin{abstract}
We investigate waveguiding of long-range surface plasmon polaritons in periodic arrays of scatterers at telecommunication wavelengths. A propagation loss of approximately 6 $\mathrm{dB} / \mathrm{mm}$ and a coupling loss of $0.5 \mathrm{~dB}$ is reported for $8-\mu \mathrm{m}$-wide channels.

C2003 Optical Society of America

OCIS codes: (240.6680) Surface plasmons; (290.4210) Multiple scattering; (250.5300) Photonic integrated circuits
\end{abstract}

Materials with periodic modulation of the refractive index also called photonic bandgap (PBG) structures, pave the way to the design of ultra-compact integrated optical circuits [1]. A new and interesting approach suggested recently is to employ the PBG technique for guiding of surface plasmon polaritons (SPPs) [2]. To overcome limitations connected to the inherently high propagation loss for SPPs propagating along a metaldielectric interface one can use a symmetric structure where a metal film is embedded in a dielectric. Such a structure supports propagation of long-range SPPs (LR-SPPs) whose loss decreases drastically with the reduction of the film thickness [3]. Guiding of light along thin metal stripes embedded in dielectric via excitation of LRSPPs has generated a lot of interest due to relatively easy fabrication, low propagation loss and efficient coupling with single mode fiber [4]. We investigate waveguiding of long-range surface plasmon polaritons in periodic arrays of scatterers with linear defects.

LR-SPP stripe waveguides are fabricated by coating a silicon substrate with a $15-\mu \mathrm{m}$-thick Benzocyclobutene (BCB) polymer layer, photolithographic patterning of stripes, gold deposition and lift-off followed by coating with the top cladding comprising another $15-\mu \mathrm{m}$-thick BCB layer. A photonic bandgap structure is obtained by applying a symmetric periodic array of gold bumps below and above the stripe waveguide. Gold bumps are patterned using electron-beam lithography and formed by metal deposition and lift-off. A microscope image of a waveguide introduced by missing rows of bumps in LR-SPPBG structure together with the detail of the corresponding mask design and a top image of light scattered from the channel is shown in. Fig. 1.
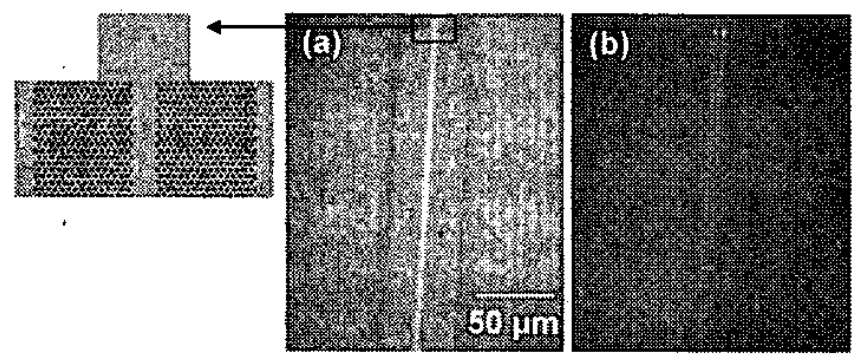

Fig. 1. 240- $\mu \mathrm{m}-$ long and $4.5-\mu \mathrm{m}$-wide LR-SPPBG channel ( $\Gamma \mathrm{K}$ orientation)

together with the detail of the mask design (a) and light scattered from the waveguide (b)

LR-SPPBG structures based on triangular lattice with different periods $(550,570,590 \mathrm{~nm})$ are optically characterized in the wavelength range from $1400 \mathrm{~nm}$ to $1600 \mathrm{~nm}$. Transmission and reflection measurements are performed on the fabricated samples containing LR-SPPBG waveguides of different lengths (from 30 to $600 \mu \mathrm{m}$ ) and widths (from 3 to 27 rows of bumps missing). The dependence of the back-reflection peak on the LR-SPPBG waveguide length is presented in Fig. 2. Typical transmission spectra for channels in structures with different lattice periods are shown in Fig. 3. We observe a sign of the LR-SPP bandgap in the $\Gamma K$ direction from transmission spectra with characteristic cut-offs and strong reflections from LR-SPPBG structures. These distinctive features in the measured wavelength dependencies of transmission and reflection are found to scale in accordance with the lattice period. 


\section{IFC6}

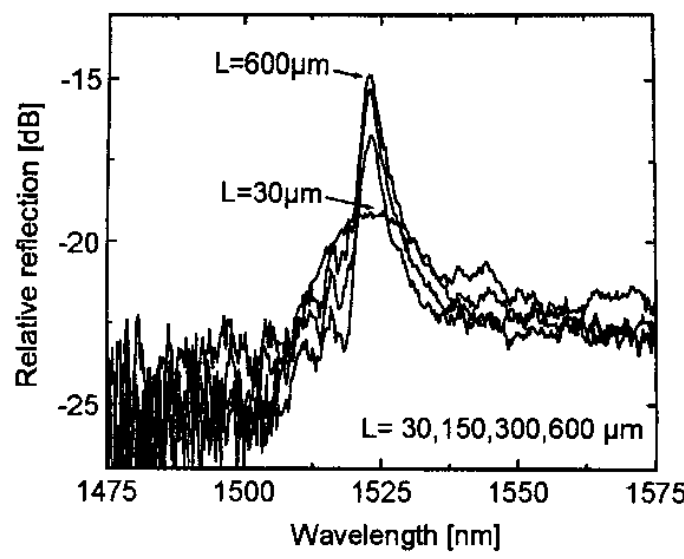

Fig. 2. Reflection from LR-SPPBG waveguides of different lengths (lattice period $570 \mathrm{~nm}, \Gamma \mathrm{K}$ orientation, channel width $3.2 \mu \mathrm{m}$ )

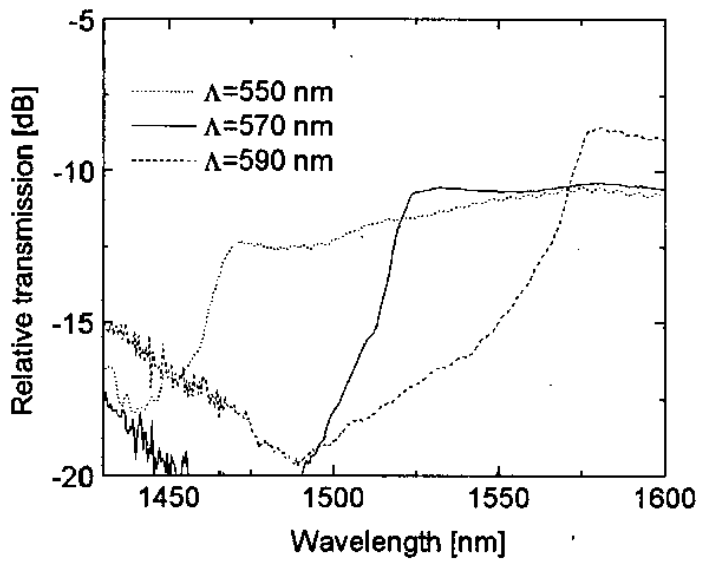

Fig. 3. Transmission through LR-SPPBG waveguides for different lattice periods (IK orientation, channel length $300 \mu \mathrm{m}$, width $4.5 \mu \mathrm{m}$ ).

From the transmission spectra for different lengths of LR-SPPBG waveguides a propagation and a coupling loss is estimated for different channel widths at the wavelength $1550 \mathrm{~nm}$. The propagation loss decreases gradually with the increasing width of the channel from $\sim 50 \mathrm{~dB} / \mathrm{mm}$ for a 1 - $\mu \mathrm{m}$-wide channel to approximately 6 $\mathrm{dB} / \mathrm{mm}$ for a 8 - $\mu \mathrm{m}$-wide channel. The coupling loss between a LR-SPPBG channel and a stripe waveguide is found to be $6 \mathrm{~dB}$ for a $1-\mu \mathrm{m}$-wide channel and $\sim 0.5 \mathrm{~dB}$ for a $8-\mu \mathrm{m}$-wide one.

We believe that combining LR-SPP waveguides with PBG channels makes these structures promising candidates for novel integrated optical components.

[1] T.F. Krauss and R. M. De La Rue, "Photonic crystals at optical wavelengths - past, present and future", Progress in Quantum Electronies 23, 51-96 (1999).

[2] S. I. Bozhevolnyi, J. Erland, K. Leosson, P. M.W. Skovgaard, and J. M. Hvam, "Waveguiding in surface plasmon polariton band gap structures", Physical Review Letters 86, 3008-3011 (2001).

[3] D. Sarid, "Long-range surface-plasma waves on very thin metal films", Physical Review Letters 47, 1927-1930 (1981).

[4] R. Charbonneau, P. Berini, E. Berolo and E. Lisicka-Shrzek, "Experimental observation of plas mon-polariton waves supported by a thin metal film of finite width," Optical Letters 25, 844-846 (2000). 